\title{
A New Approach for Accurate Prediction of Liquid Loading of Directional Gas Wells in Transition Flow or Turbulent Flow
}

\author{
Ruiqing Ming ${ }^{1,2}$ and Huiqun $\mathrm{He}^{2}$ \\ ${ }^{1}$ Research Institute of Petroleum Exploration \& Development, Beijing 100083, China
}

${ }^{2}$ CNPC Drilling Research Institute, Beijing 100195, China

Correspondence should be addressed to Ruiqing Ming; 411478802@qq.com

Received 2 March 2017; Accepted 3 May 2017; Published 23 May 2017

Academic Editor: Franco Tassi

Copyright (C) 2017 Ruiqing Ming and Huiqun He. This is an open access article distributed under the Creative Commons Attribution License, which permits unrestricted use, distribution, and reproduction in any medium, provided the original work is properly cited.

\begin{abstract}
Current common models for calculating continuous liquid-carrying critical gas velocity are established based on vertical wells and laminar flow without considering the influence of deviation angle and Reynolds number on liquid-carrying. With the increase of the directional well in transition flow or turbulent flow, the current common models cannot accurately predict the critical gas velocity of these wells. So we built a new model to predict continuous liquid-carrying critical gas velocity for directional well in transition flow or turbulent flow. It is shown from sensitivity analysis that the correction coefficient is mainly influenced by Reynolds number and deviation angle. With the increase of Reynolds number, the critical liquid-carrying gas velocity increases first and then decreases. And with the increase of deviation angle, the critical liquid-carrying gas velocity gradually decreases. It is indicated from the case calculation analysis that the calculation error of this new model is less than $10 \%$, where accuracy is much higher than those of current common models. It is demonstrated that the continuous liquid-carrying critical gas velocity of directional well in transition flow or turbulent flow can be predicted accurately by using this new model.
\end{abstract}

\section{Introduction}

Gas well is usually exploited by using depletion type. The ultimate recovery of pure gas reservoir is generally more than $90 \%$, which is far more than the oil recovery [1]. Liquid loading is the most common phenomenon in gas wells. And the main cause of this phenomenon is that in the later period during the gas well production, the formation pressure, gas velocity, and liquid-carrying capacity will be reduced, and the part of formation water in the wellbore will stay in well bottom causing fluid accumulation [2,3]. Liquid loading will create an increased backpressure on the formation and reduce production pressure differential, which decreases the gas rate and even kills the gas well $[4,5]$. Based on the theory of hydrodynamics, the formation water can be drawn to the surface when current gas velocity is higher than critical gas velocity. Therefore, it is of great significance to accurately predict the critical gas velocity in order to avoid liquid loading and increase gas recovery rate.
Under the condition of vertical well and laminar flow $\left(10^{4} \leq \operatorname{Re} \leq 2 \times 10^{5}\right)$, Turner et al. [6] assumed that droplets in gas wells are spherical and derived continuous liquid-carrying critical gas velocity formula. In order to make calculation convenient, the drag coefficient was taken as 0.44 . In order to fit their experimental data, the calculated results were improved by $20 \%$ upward. Coleman et al. $[7,8]$ applied Turner model to their experimental data. They concluded that the Turner model is suitable for wellhead pressure less than $3.45 \mathrm{MPa}$ and that the $20 \%$ upward adjustment is not necessary to calculate the critical gas velocity. Li et al. [9] assumed that droplets in gas wells are elliptical and derived a new formula for calculating the critical liquid-carrying gas velocity, whose result was only $1 / 3$ of the result calculated by the Turner model. Later, many scholars have made various changes to the Turner model and the Li model [9], but they are only suitable for the vertical well and laminar flow. Based on the previous study [6-8], Nosseir et al. [10] considered the influence of flow regime on the calculation result. And 
they took drag coefficient as 0.2 and extended the application scope of the Turner model to transition flow and turbulence flow $\left(2 \times 10^{5} \leq \operatorname{Re} \leq 10^{6}\right)$. Based on the Turner model, Zhou and Yuan [11] believed that liquid concentration will also affect the continuous liquid-carrying capacity and thereby proposed a new model to calculate critical gas velocity. Based on the Li model [9], Luan and He [12] used dimensionless loss factor to evaluate gas energy loss and took the impact of the variation of gas lift efficiency into consideration and thereby derived a new formula to calculate critical gas velocity. At low pressure, the calculated results of the model are better than those calculated by the Turner model and the Li model.

Belfroid et al. [13] proposed that using the Turner model to predict critical gas velocity in directional well will cause large errors and adjusted the Turner model with the Fiedler shape function to fit well data for all inclination angles. Based on the force analysis of droplet in directional well, Yang et al. [14] put forward the calculation method of continuous liquidcarrying critical gas velocity in directional well and laminar flow condition. They believed that droplet is not impacted by the tubing wall and always rises up along the central line of the tubing. Based on the force analysis of liquid film in directional well, Chen et al. [15] derived a new formula for evaluating liquid-carrying capacity in directional well and laminar flow condition.

As known from the standard experimental drag curve, drag coefficient fluctuates heavily under the condition of transition flow and turbulence flow $\left(2 \times 10^{5} \leq \operatorname{Re} \leq 10^{6}\right)$. It is obviously unreasonable to take drag coefficient as a fixed value. Engelund and Hansen [16], Clift and Gauvin [17], and Yen [18] fitted the experimental data, respectively, and derived the formulas relating to drag coefficient and Reynolds number in laminar flow $\left(10^{4} \leq \mathrm{Re} \leq 2 \times 10^{5}\right)$. Later, Barati et al. [19] used a multigene Genetic Programming (GP) procedure to obtain a hyperbolic tangent function about the two parameters, whose result was more accurate than before in laminar flow.

At present, there are more and more directional gas wells under the condition of transition flow and turbulence flow, such as Sulige gas field in China. And the calculation model which meets the above conditions is not established. When the existing models are used to calculate the critical gas velocity, the computational error will be large. Therefore, in the directional gas well, it is necessary to consider the impact of Reynolds number on drag coefficient under the condition of transition flow and turbulence flow. So the calculation model needs to be modified.

This paper presents a new model to calculate critical gas velocity of directional well in transition flow and turbulence flow. The new model analyzes the force state of droplet in a new way. And gas field data in Chinese western block and northern block were employed to validate the new model.

\section{New Model}

Zhao et al. [20] did some experiments and concluded that the liquid phase in the directional well is dispersed into small droplets to be taken out of the wellbore by natural gas, which means that the droplet model is more reliable than the liquid

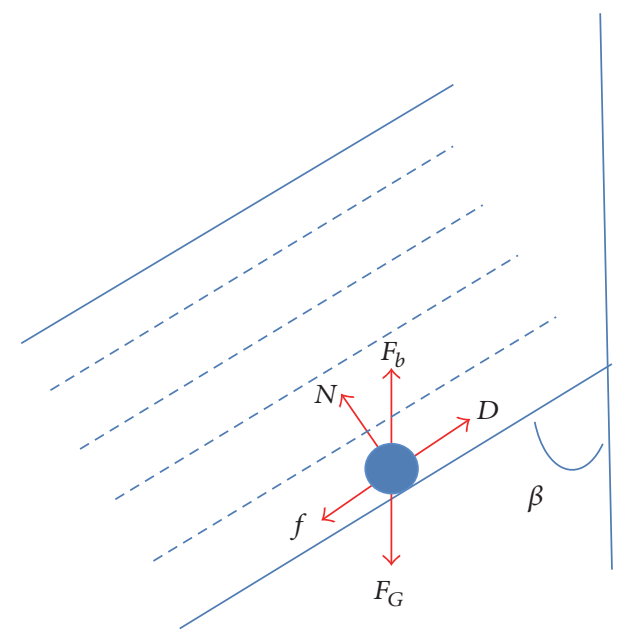

FIgURE 1: Force balance of droplet in directional well, where $\beta$ is the deviation angle, degrees, with $\beta=90^{\circ}$ which represents the horizontal well; $D$ is the drag force of airstream on droplet, $\mathrm{N} ; F_{G}$ is the droplet gravity, $\mathrm{N} ; f$ is the wall friction to the droplet, $\mathrm{N} ; \mathrm{N}$ is the bracing force, $\mathrm{N} ; F_{b}$ is the buoyancy force, $\mathrm{N}$.

film model in the process of liquid-carrying. We assume that the droplet is spherical and the collision between droplets is neglected. In critical state, the velocity of liquid phase and gas phase is basically the same, so the droplet is free from the friction of airstream. We conclude that the droplet will only be carried along the tubing out of wellbore; otherwise the horizontal component of $D$ (see Figure 1) cannot be balanced. The force balance is shown in Figure 1.

For the droplet (see Figure 1), we get the force balance:

$$
\begin{aligned}
& F_{b} \cos \beta+D=F_{G} \cos \beta+f, \\
& N+F_{b} \sin \beta=F_{G} \sin \beta .
\end{aligned}
$$

It is assumed that the sphere surface is smooth and the equivalent diameter is $d, \mathrm{~m} ; F_{G}, F_{b}$, and $D$ can be expressed as

$$
\begin{aligned}
F_{G} & =\frac{\pi}{6} d^{3} \rho_{l} g, \\
F_{b} & =\frac{\pi}{6} d^{3} \rho_{g} g, \\
D & =\frac{\pi}{8} d^{2} \rho_{g} C_{d} u^{2},
\end{aligned}
$$

where $\rho_{l}$ is the liquid density, $\mathrm{kg} / \mathrm{m}^{3} ; g$ is gravitational acceleration, $\mathrm{m} / \mathrm{s}^{2} ; \rho_{g}$ is the gas density, $\mathrm{kg} / \mathrm{m}^{3} ; C_{d}$ is the drag coefficient, dimensionless; $u$ is the critical gas velocity, $\mathrm{m} / \mathrm{s}$.

$f$ is the wall friction to the droplet, $\mathrm{N}$, which can be expressed as

$$
f=\lambda N
$$

where $\lambda$ is the wall friction factor, dimensionless, which is related to tubing roughness and Reynolds number. 
Combining (2), (3), and (4), we can express the wall friction as

$$
f=\frac{\pi}{6} g \lambda d^{3}\left(\rho_{l}-\rho_{g}\right) \sin \beta .
$$

In addition, the droplet is affected by the surface tension that makes it complete and the inertia force that causes it to rupture. When the Weber number ranges from 20 to 30, the droplet will break. Turner et al. [6] concluded that if the maximum diameter droplet is taken out of the wellbore, liquid loading will not happen. Li et al. [1] took the Weber number as 30 , and the maximum diameter of droplet can be expressed as

$$
d_{m}=\frac{30 \sigma}{\left(\rho_{g} u^{2}\right)},
$$

where $\sigma$ is the gas-liquid interfacial tension, $\mathrm{N} ; d_{m}$ is the maximum droplet diameter, $\mathrm{m}$.

Substituting (3), (5), and (6) into (1), we can derive the general calculation model of continuous liquid-carrying critical gas velocity:

$$
u=\sqrt[4]{\frac{40 g \sigma\left[\left(\rho_{l}-\rho_{g}\right) \cos \beta+\lambda\left(\rho_{l}-\rho_{g}\right) \sin \beta\right]}{C_{d} \rho_{g}{ }^{2}}} .
$$

The wall friction factor is related to the wall roughness and Reynolds number, and the conventional friction factor ranges from 0.01 to 0.1 . Li et al. [1] and Chen et al. [15] demonstrated that the wall friction factor has little impact on critical gas velocity. Taking $\lambda$ as 0.1 , we can get

$$
u=4.5 \sqrt[4]{\frac{0.1 \sin \beta+\cos \beta}{C_{d}}}\left(\sqrt[4]{\frac{\left(\rho_{l}-\rho_{g}\right) \sigma}{\rho_{g}^{2}}}\right) .
$$

As known by the standard experimental drag curve, drag coefficient fluctuates heavily under the condition of transition flow and turbulence flow $\left(2 \times 10^{5} \leq \operatorname{Re} \leq 10^{6}\right)$. It is obviously unreasonable to take drag coefficient as a fixed value. Thus, we use SPSS to conduct nonlinear fitting of the experimental data in transition flow and turbulence flow (see Table 1 and Figure 2).

As can be seen from Table 1 and Figure 2, $R$ square of cubic equation is 0.940 , which shows that the fitting of this model is better than others. The $F$ statistic was 25.902 , indicating that regression model fitting results are good. Therefore, we take the cubic model in transition flow and turbulence flow:

$$
\begin{aligned}
C_{d}= & -3.316 \times 10^{-18} \mathrm{Re}^{3}+7.3 \times 10^{-12} \mathrm{Re}^{2}-4.918 \\
& \times 10^{-6} \mathrm{Re}+1.143 .
\end{aligned}
$$

It can be seen from Table 2 and (8) that, as Reynolds number increases, drag coefficient decreases and critical gas velocity increases in transition flow and turbulence flow. Nosseir et al. [10] proposed that drag coefficient can be taken as 0.2 in transient flow and turbulence flow $\left(2 \times 10^{5} \leq \mathrm{Re} \leq\right.$

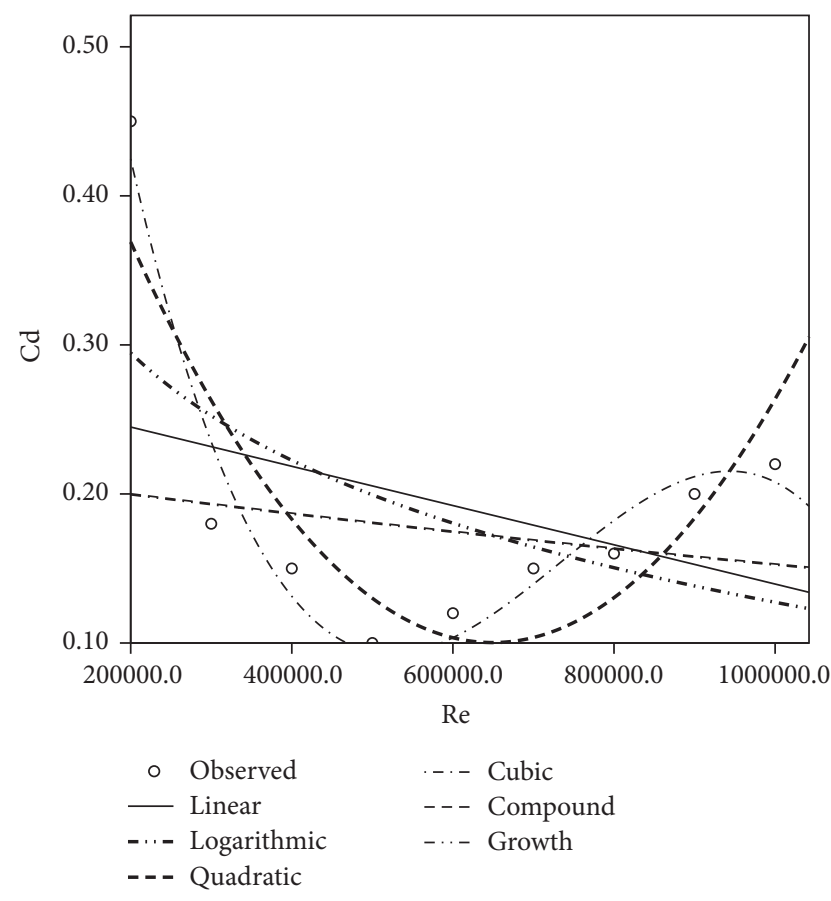

FIGURE 2: Nonlinear fitting graph.

$\left.10^{6}\right)$. It can be clearly seen from Table 2 that when Reynolds number ranges from $3.2 \times 10^{5}$ to $10^{6}$, the result obtained by Nosseir model is less than the actual data and Nosseir model will cause considerable errors. Zhao et al. [21] used Nosseir model to predict critical gas velocity in Sulige gas field, but the calculation results have a large deviation.

In a word, the critical liquid-removal gas velocity of directional well in transient flow and turbulence flow can be written as follows:

$$
\begin{aligned}
u= & B\left(\sqrt[4]{\frac{\left(\rho_{l}-\rho_{g}\right) \sigma}{\rho_{g}{ }^{2}}}\right), \\
C_{d}= & -3.316 \times 10^{-18} \mathrm{Re}^{3}+7.3 \times 10^{-12} \mathrm{Re}^{2}-4.918 \\
& \times 10^{-6} \mathrm{Re}+1.143 .
\end{aligned}
$$

$B$ number is a correction term, which can be introduced:

$$
B=4.5 \sqrt[4]{\frac{0.1 \sin \beta+\cos \beta}{C_{d}}} .
$$

\section{Correction Term}

As can be seen from (10) and (11), the correction term is mainly dependent upon Reynolds number and deviation angle. As shown in Figure 3, the correction term is plotted as function of deviation angle at different Reynolds number.

It can be seen from Figure 3 and Table 3 that, with the increase of Reynolds number, the correction term increases significantly and then decreases slowly, but it shows a rising trend in general. Furthermore, with the increase of the 


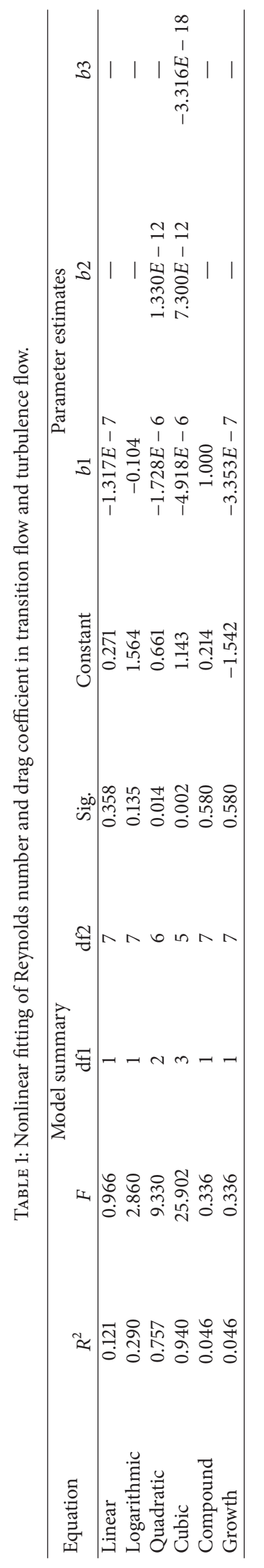


TABLE 2: Fitting drag coefficient from (9).

\begin{tabular}{lccc}
\hline Reynolds number $\left(10^{5}\right)$ & Fitting drag coefficient & Reynolds number $\left(10^{5}\right)$ & Fitting drag coefficient \\
\hline 2.1 & 0.40 & 3.9 & 0.14 \\
2.3 & 0.36 & 4.1 & 0.13 \\
2.4 & 0.34 & 4.2 & 0.12 \\
2.6 & 0.30 & 4.4 & 0.11 \\
2.9 & 0.25 & 4.7 & 0.10 \\
3.0 & 0.24 & 4.8 & 0.10 \\
3.1 & 0.22 & 4.9 & 0.10 \\
3.2 & 0.21 & 5.0 & 0.09 \\
3.4 & 0.18 & 5.5 & 0.09 \\
3.7 & 0.15 & 7.0 & 0.14 \\
3.8 & 0.14 & 8.0 & 0.18 \\
\hline
\end{tabular}

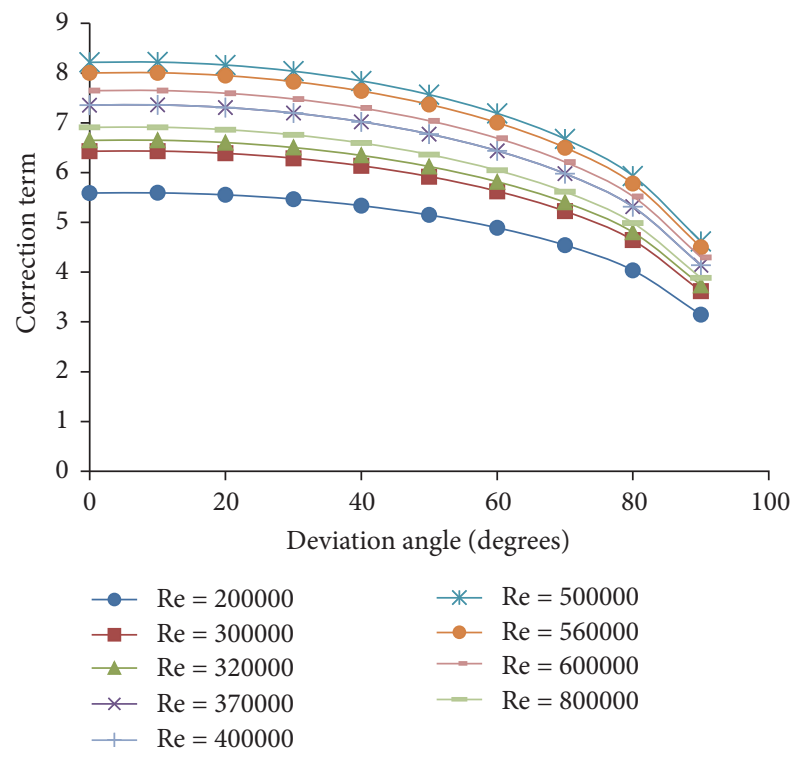

FIGURE 3: Relationship between deviation angle and correction coefficient under different Reynolds number.

correction term, the critical gas velocity increases and liquidcarrying capacity decreases. With the increase of deviation angle, the influence of Reynolds number on the correction term is becoming smaller. While at an identical Reynolds number, as the deviation angle increases, the correction term decreases, and this decreasing trend increases as the pipe deviates, which means that critical gas velocity decreases and liquid-carrying capacity is enhanced. This is because as the deviation angle increases, the gravitational force in the flow direction decreases which will reduce the critical gas velocity [22]. For the convenience of site application, the curve in Figure 3 is transformed into a correction term reference table (see Table 3). And the noticed point is that the table should be modified based on the actual gas field conditions.

\section{Application of Field Data}

In order to validate the applicability to directional gas well in transition flow and turbulence flow, a large amount of field data collected from Chinese gas reservoir including both northern block and western block is used to verify the prediction accuracy of the new model. In this paper, calculation results obtained by the new model will be compared with those from other models.

4.1. Application of Field Data in Chinese Western Block. Western block consists of 16 directional gas wells, which includes 4 unloaded wells and 12 loaded wells. Among all the directional gas wells in the block, the Reynolds number ranges from $2.3 \times 10^{5}$ to $7.7 \times 10^{5}$ and the deviation angle ranges from $24^{\circ}$ to $50^{\circ}$. The detailed field data are listed in Table 4. And the gas rate is converted to the superficial velocity used to compare with the calculated critical gas velocity, as shown in column 7. Column 9 and column 11 represent the critical gas velocity calculated by Belfroid model and by new model, respectively. If the critical gas velocity is higher than current gas velocity, the well is considered to be loaded. On the contrary, if the critical gas velocity is lower than current gas velocity, water cannot accumulate in bottom hole and the well is considered to be unloaded. Column 10 and column 12 represent the predicting status from the two models. Column 13 represents the test status which is the actual status of 16 directional gas wells in Chinese western block. If the predicting status is consistent with the test status, then the predicted result is correct. On the other hand, if the predicting status is inconsistent with the test status, the predicted result is incorrect.

As can be seen in Table 4, when the Belfroid model is used to predict liquid loading status, 6 wells are predicted incorrectly, including well number 3 , well number 4 , well number 8 , well number 9 , well number 11 , and well number 14 , with $62.5 \%$ accuracy. The main reason is due to the fail to consider the influence of Reynolds number on drag coefficient in transition flow and turbulent flow. When the new model is used to predict liquid loading status, only 2 wells are predicted incorrectly, including well number 3 and well number 4 , with up to $87.5 \%$ accuracy, which is in good agreement with the actual state. The prediction results show great improvement over the Belfroid model. Therefore, in the aspect of predicting liquid loading, the new model is better than the Belfroid model. 


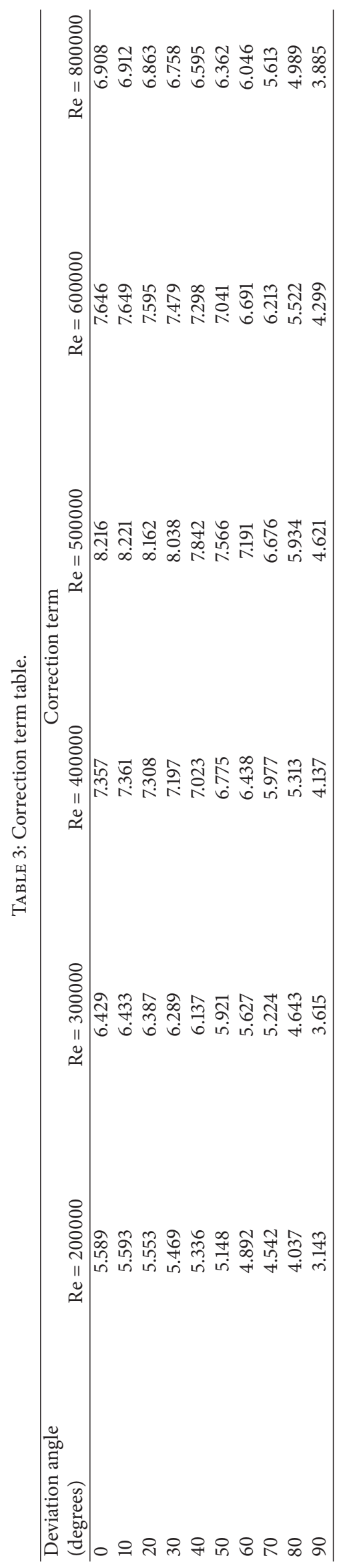




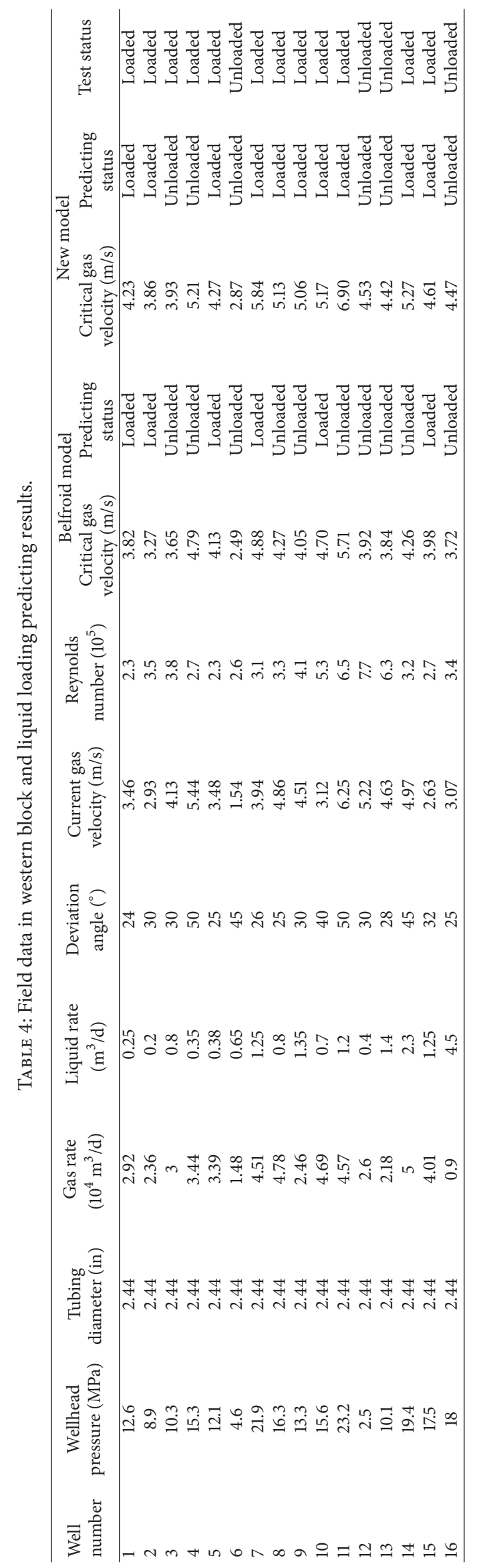


TABLE 5: Field data of 4 wells in northern block.

\begin{tabular}{lcccc}
\hline Well number & A1 & A2 & B1 & B2 \\
\hline Deviation angle $/\left(^{\circ}\right)$ & 24.4 & 30 & 33 & 30 \\
Reynolds number $/ 10^{5}$ & 3.5 & 2.7 & 3.9 & 2.99 \\
Tubing size/in & 2.44 & 2.44 & 3 & 2.99 \\
Wellhead pressure $/ \mathrm{MPa}$ & 3 & 2.65 & 1.8 & 2.85 \\
Gas rate $/ 10^{4} \mathrm{~m}^{3} \cdot \mathrm{d}^{-1}$ & 0.5 & 0.45 & 0.97 & 3 \\
Liquid rate $/ \mathrm{m}^{3} \cdot \mathrm{d}^{-1}$ & 0.14 & 0.27 & Unloaded & Unloaded \\
Test status & Loaded & Loaded & & \\
\hline
\end{tabular}

TABLE 6: Calculated results of different models.

\begin{tabular}{|c|c|c|c|c|c|c|c|c|}
\hline \multirow[b]{2}{*}{ Model } & \multicolumn{2}{|c|}{$\mathrm{A} 1$} & \multicolumn{2}{|c|}{$\mathrm{A} 2$} & \multicolumn{2}{|c|}{ B1 } & \multicolumn{2}{|c|}{ B2 } \\
\hline & $\begin{array}{l}\text { Critical velocity/ } \\
\qquad(\mathrm{m} / \mathrm{s})\end{array}$ & Error & $\begin{array}{c}\text { Critical } \\
\text { velocity/ } \\
(\mathrm{m} / \mathrm{s})\end{array}$ & Error & $\begin{array}{c}\text { Critical } \\
\text { velocity/ } \\
(\mathrm{m} / \mathrm{s})\end{array}$ & Error & $\begin{array}{c}\text { Critical } \\
\text { velocity/ } \\
(\mathrm{m} / \mathrm{s})\end{array}$ & Error \\
\hline Critical velocity & 2.91 & - & 0.9 & - & 2 & - & 1.83 & - \\
\hline Turner model & 4.6 & $58 \%$ & 1.4 & $56 \%$ & 3.2 & $60 \%$ & 2.97 & $62 \%$ \\
\hline Belfroid model & 4.0 & $37 \%$ & 1.33 & $48 \%$ & 2.8 & $40 \%$ & 2.67 & $46 \%$ \\
\hline Chen model & 3.5 & $20 \%$ & 0.53 & $41 \%$ & 2.7 & $35 \%$ & 1.2 & $34 \%$ \\
\hline New model & 2.83 & $3 \%$ & 0.84 & $7 \%$ & 1.95 & $3 \%$ & 1.74 & $5 \%$ \\
\hline
\end{tabular}

4.2. Application of Field Data in Chinese Northern Block. There are 4 wells in Chinese northern block, including A1, $\mathrm{A} 2, \mathrm{~B} 1$, and B2. A1 and A2 have been shut in due to bottom overstock liquid terrible. On the other hand, B1 and B2 are being produced. The detailed field data are listed in Table 5. In this paper, the new model and several common models are used to calculate critical liquid-carrying gas velocity. The results are shown in Table 6.

As can be seen in Tables 5 and 6, under the condition of transition flow and turbulent flow, the error of the calculated results by the new model is less than $10 \%$, which is more accurate than the common methods. The Turner model, as a whole, overestimates the critical gas velocity for directional well in transition flow and turbulent flow, which is possibly due to the overlook of the impact of deviation angle and flow regime on critical gas velocity. The prediction results of Belfroid model are better than Turner model. But the prediction error is still large, which may be because the model fails to consider the impact of flow regime on critical gas velocity. In addition, the prediction error of Chen model [15] is also large. This is mainly because the model is obtained by force analysis of liquid film, but the droplet model is more reliable than the liquid film model in the process of liquidcarrying [20].

\section{Conclusion}

(1) The balance of forces acting on droplet in directional gas well is analyzed. By nonlinear simulation of the experiment data $\left(2 \times 10^{5} \leq \operatorname{Re} \leq 10^{6}\right)$, we obtain a function relating to Reynolds number and drag coefficient. Eventually we derive a new model to predict critical gas velocity of directional well in transition flow and turbulent flow.
(2) A correction term formula is introduced. The impact of deviation angle and Reynolds number on the correction term is discussed. And a correction term reference table is given for the convenience of site application.

(3) A large quantity of field data collected from Chinese gas reservoir, including both northern block and western block, is used to verify the prediction accuracy of the new model. It can be consistently seen that the new model is superior to the several common models in predicting liquid loading of directional wells in transition flow and turbulent flow.

\section{Nomenclature}

$\beta$ : Deviation angle, degrees

$D$ : Drag force of airstream on droplet, $\mathrm{N}$

$F_{G}$ : Droplet gravity, $\mathrm{N}$

$f$ : Wall friction to the droplet, $\mathrm{N}$

$N$ : Bracing force, $\mathrm{N}$

$F_{b}$ : Buoyancy force, $\mathrm{N}$

$d$ : Equivalent diameter, $\mathrm{m}$

$d_{m}$ : Maximum droplet diameter, $\mathrm{m}$

$\rho_{l}$ : Liquid density, $\mathrm{kg} / \mathrm{m}^{3}$

$g:$ Gravity acceleration, $\mathrm{m} / \mathrm{s}^{2}$

$\rho_{g}$ : Gas density, $\mathrm{kg} / \mathrm{m}^{3}$

$C_{d}$ : Drag coefficient, dimensionless

$u$ : Critical gas velocity, $\mathrm{m} / \mathrm{s}$

$\lambda$ : Wall friction factor, dimensionless

$\sigma$ : Gas-liquid interfacial tension, $\mathrm{N}$

Re: Reynolds number, dimensionless

$B$ : $B$ number, dimensionless. 


\section{Conflicts of Interest}

The authors declare that there are no conflicts of interest regarding the publication of this paper.

\section{Acknowledgments}

This work was supported by project of CNPC Drilling Research Institute (Grant no. 2015F-2001-01).

\section{References}

[1] L. Li, L. Zhang, B. Yang, Y. Yin, and D. Li, "Prediction method of critical liquid-carrying flow rate for directional gas wells," Oil \& Gas Geology, vol. 33, no. 4, pp. 650-654, 2012.

[2] G. Chupin, B. Hu, T. Haugset, J. Sagen, and M. Claudel, "Integrated wellbore/reservoir model predicts flow transients in liquid-loaded gas wells," in Proceedings of the SPE Annual Technical Conference and Exhibition, Anaheim, Calif, USA, November 2007.

[3] W. Schiferli, S. P. C. Belfroid, S. Savenko, C. A. M. Veeken, and B. Hu, "Simulating liquid loading in gas wells," in Proceedings of the 7th North American Conference on Multiphase Technology, Banff, Canada, June, 2010.

[4] A. Fadairo, D. Femi-Oyewole, and O. Falode, "An improved predictive tool for liquid loading in a gas well," in Proceedings of the SPE Nigeria Annual International Conference and Exhibition, Lagos, Nigeria, August 5-7, 2013.

[5] J. F. Lea and H. V. Nickens, "Solving gas-well liquid-loading problems," Journal of Petroleum Technology, vol. 56, no. 4, pp. 30-36, 2004.

[6] R. G. Turner, M. G. Hubbard, and A. E. Dukler, "Analysis and prediction of minimum flow rate for the continuous removal of liquids from gas wells," Journal of Petroleum Technology, vol. 21, no. 11, pp. 1475-1482, 1969.

[7] S. B. Coleman, H. B. Clay, D. G. McCurdy, and L. H. Norris, "A new look at predicting gas-well load-up," Journal of Petroleum Technology, vol. 43, no. 3, pp. 329-333, 1991.

[8] S. B. Coleman, H. B. Clay, D. G. McCurdy, and L. H. Norris, "Understanding gas-well load-up behavior," Journal of Petroleum Technology, vol. 43, no. 3, pp. 334-338, 1991.

[9] M. Li, S. Li, and L. Sun, "New view on continuous-removal liquids from gas wells," SPE Production \& Facilities, vol. 17, no. 1, pp. 42-46, 2002.

[10] M. A. Nosseir, T. A. Darwich, M. H. Sayyouh, and M. El Sallaly, "A new approach for accurate prediction of loading in gas wells under different flowing conditions," SPE Production and Facilities, vol. 15, no. 4, pp. 241-246, 2000.

[11] D. Zhou and H. Yuan, "A New model for predicting gas-well liquid loading," SPE Production \& Operations, vol. 25, no. 2, pp. 172-181, 2010.

[12] G. Luan and S. He, "A new model for the accurate prediction of liquid loading in low-pressure gas wells," Journal of Canadian Petroleum Technology, vol. 51, no. 6, pp. 493-498, 2012.

[13] S. P. C. Belfroid, W. Schiferli, G. J. N. Alberts, C. A. M. Veeken, and E. Biezen, "Prediction onset and dynamic behaviour of liquid loading gas wells," in Proceedings of the SPE Annual Technical Conference and Exhibition, Society of Petroleum Engineers, pp. 21-24, Denver, Colo, USA, 2008.

[14] W. M. Yang, M. Wang, L. Chen, J. C. Wu, and P. X. Yu, "A prediction model on calculation of continuous liquid carrying critical production of directional gas wells," Natural Gas Industry, vol. 29, no. 5, pp. 82-84, 2009.

[15] D. C. Chen, Y. Yao, G. Fu, H. X. Meng, and S. X. Xie, "A new model for predicting liquid loading in deviated gas wells," Journal of Natural Gas Science and Engineering, vol. 34, pp. 178184, 2016.

[16] F. Engelund and E. Hansen, Monograph on Sediment Transport in Alluvial Streams, Monograpsh Denmark Technical University, Hydraulic Lab, Denmark, 1967.

[17] R. Clift and W. H. Gauvin, "The motion of particles in turbulent gas streams," Revista Argentina de Cardiología, vol. 82, no. 3, pp. $14-28,1970$.

[18] B. C. Yen, Sediment fall velocity in oscillating flow, University of Virginia, USA, 1992.

[19] R. Barati, S. A. A. S. Neyshabouri, and G. Ahmadi, "Development of empirical models with high accuracy for estimation of drag coefficient of flow around a smooth sphere: an evolutionary approach," Powder Technology, vol. 257, no. 5, pp. 11-19, 2014.

[20] Z. J. Zhao, T. Liu, J. Xu, J. Zhu, and Y. Yang, "Stable fluid-carrying capacity of gas wells," Natural Gas Industry, vol. 35, no. 6, pp. 59-63, 2015.

[21] B. B. Zhao, X. H. Bai, D. J. Chen, X. R. Li, and W. B. Zhao, "Effect assessment of drainage gas recovery through velocity string and its new application area," China Petroleum Machinery, vol. 40, no. 11, pp. 62-65, 2012.

[22] S. Luo, M. Kelkar, E. Pereyra, and C. Sarica, "A new comprehensive model for predicting liquid loading in gas wells," SPE Production and Operations, vol. 29, no. 4, pp. 337-349, 2014. 

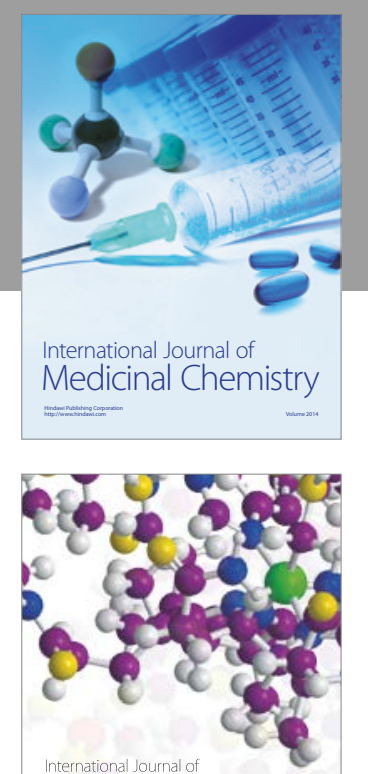

Carbohydrate Chemistry

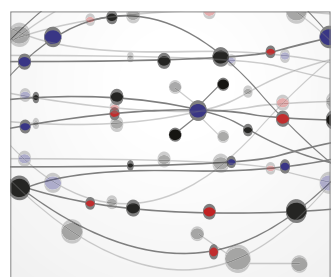

The Scientific World Journal
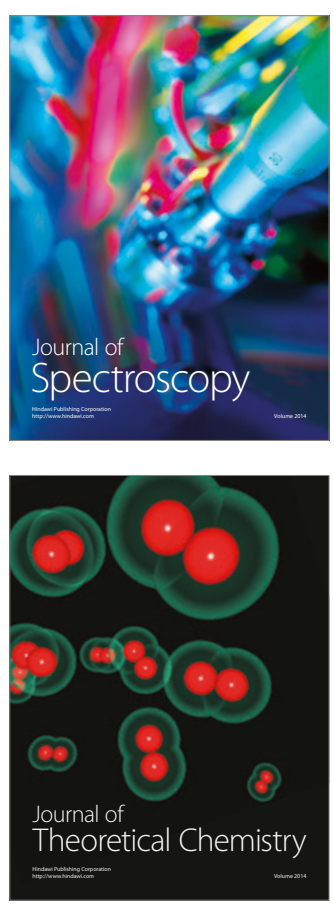
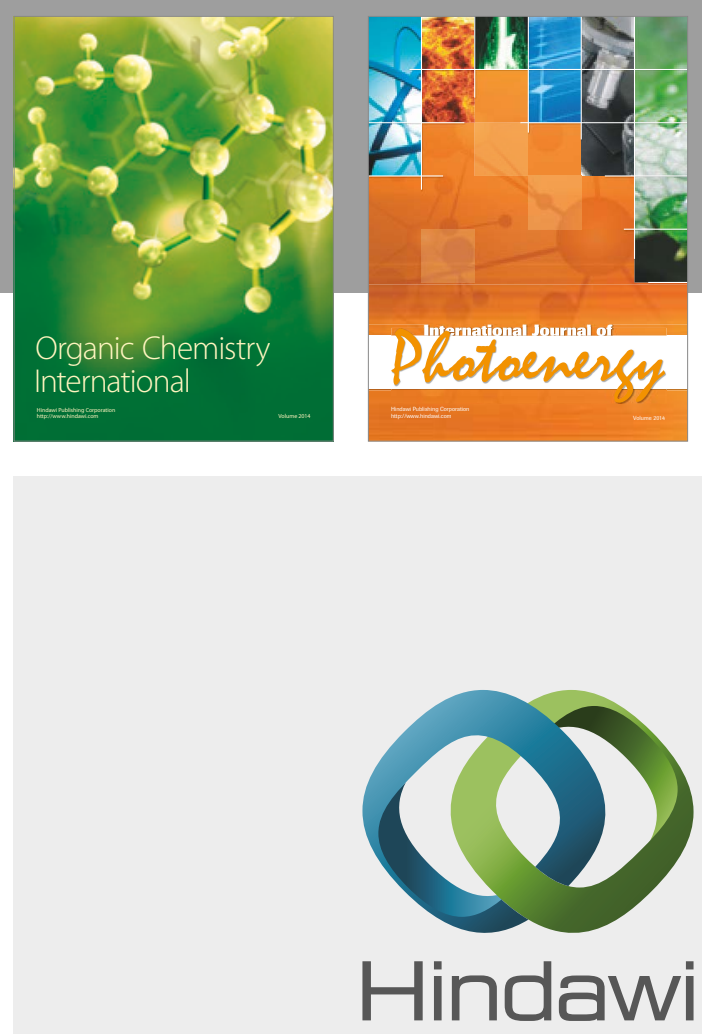

Submit your manuscripts at

https://www.hindawi.com

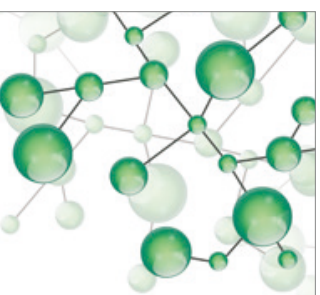

International Journal of

Inorganic Chemistry

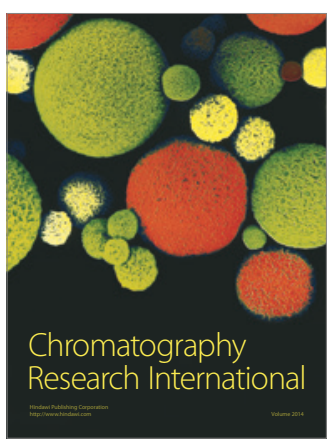

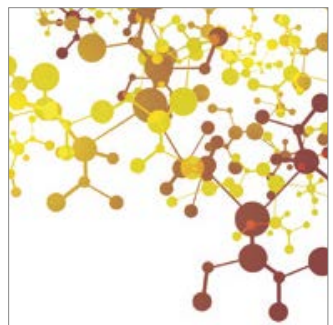

Applied Chemistry
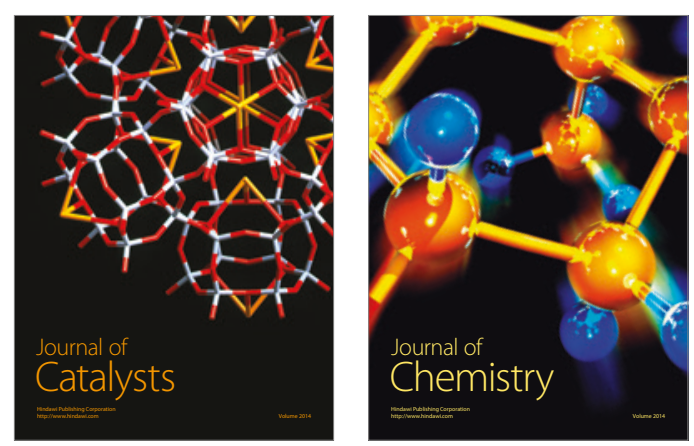
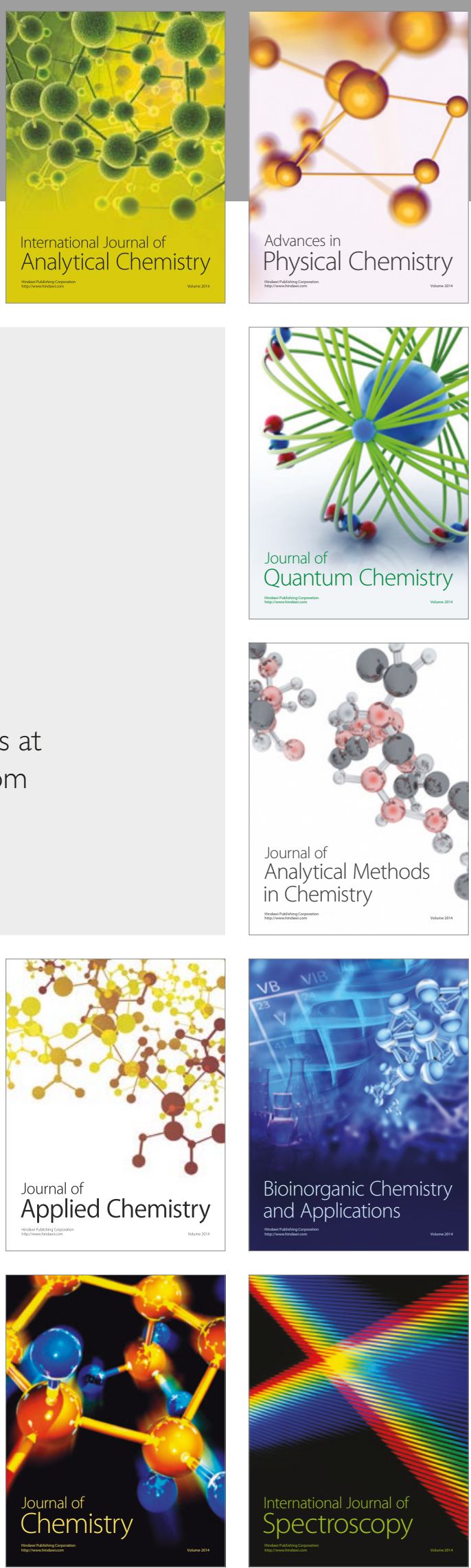